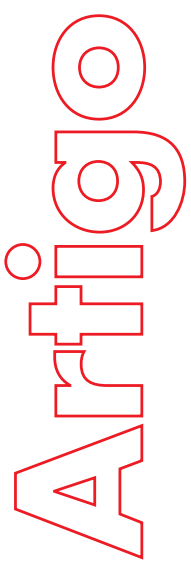

Revista

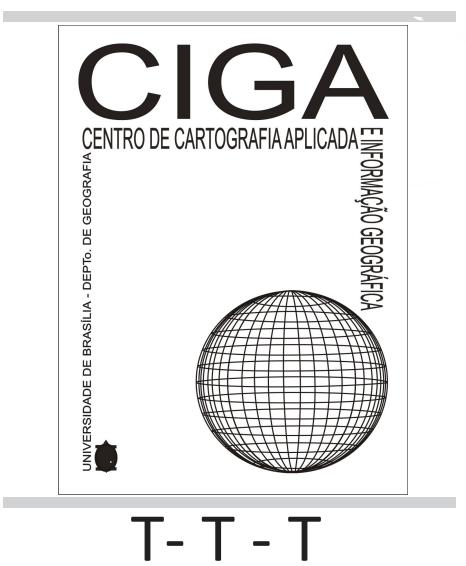

Revista Eletrônica: Tempo - Técnica - Território, V.11, N.2 (2020), 36:51 ISSN: 2177-4366

\section{ANÁLISE DA ABORDAGEM DIDATICA DA CULTURA AFRICANA E AFRO BRASILEIRA NO LIVRO GEOGRAFIA ESPACO E VIVENCIA - 8' AÑO}

\author{
William José De Carvalho Filho
}

p. $36-51$

Como citar este artigo:

Filho, W.J. C.

ANÁLISE DA ABORDAGEM DIDÁTICA DA CULTURA AFRICANA E AFRO BRASILEIRA NO LIVRO GEOGRAFIA ESPAÇO E VIVÊNCIA - 8 ANO

Revista Eletrônica: Tempo - Técnica - Território, v.11, n.2

(2020),p.36:51 ISSN: 2177-4366.

Disponível em: http://periodicos.unb.br/index.php/ciga/

Este obra está licenciado com uma Licença Creative Commons Atribuição - Não Comercial 4.0 Internacional. 


\title{
ANÁLISE DA ABORDAGEM DIDÁTICA DA CULTURA AFRICANA E AFROBRASILEIRA NO LIVRO GEOGRAFIA ESPAÇO E VIVÊNCIA - $8^{\circ}$ ANO
}

\author{
William José De Carvalho Filho \\ Graduando em Enegenharia Aeroespacial pela Universidade de Brasília \\ Disciplina GEOAFRO - 1 Semestre 2020. E-mail: jose7.filho@gmail.com
}

RESUMO: Um país com uma matriz étnico-cultural tão rica quanto a do Brasil é difícil de se encontrar. Seja pela heterogeneidade de sua formação, tanto em suas origens quanto no intervalo de tempo compreendido, a cultura e identidade brasileiras são resultado de uma fermentação e amadurecimentos de inúmeras etnias africanas, culturas indígenas e costumes europeus. Sendo assim, este artigo propõe a realização de análise crítica de um livro didático, destinado a estudantes do $8^{\circ}$ ano do Ensino Fundamental, a partir das presenças ou ausências do conteúdo de Geografia e cultura afro-brasileiras. Para tal, é necessário que se analise qualitativamente o material didático ao qual o sistema de ensino está sendo submetido, verificando se ele cumpre tanto a lei 10.639/2003 quanto se instrumentaliza o estudante para o desenvolvimento das habilidades estabelecidas na BNCC. Como o volume traz uma abordagem em escala global, não necessariamente foca nos aspectos constitucionais da população e território brasileiros, embora tal discussão seja levantada em atividades a serem desenvolvidas.

Palavras-chave: Livro didático; Geografia Afrobrasileira; BNCC; Lei 10639/2003

ABSTRACT: A country with an ethnic-cultural matrix as rich as that of Brazil is difficult to find. Whether due to the heterogeneity of its formation, both in its origins and in the time span understood, Brazilian culture and identity are the result of the fermentation and maturation of innumerable African ethnicities, indigenous cultures and European customs. Therefore, this article proposes to carry out a critical analysis of a textbook, aimed at students in the 8th year of elementary school, based on the presence or absence of the content of Afro-Brazilian geography and culture. For that, it is necessary to qualitatively analyze the didactic material to which the education system is being 
submitted, verifying if it complies with both Law 10.639 / 2003 and the student is instrumental in the development of the skills established in the BNCC. As the volume brings an approach on a global scale, it does not necessarily focus on the constitutional aspects of the Brazilian population and territory, although such a discussion is raised in activities to be developed.

Keywords: Textbook; Afro-brazilian Geography; BNCC; Law 10639/2003.

\section{Introdução}

O livro escolhido (Geografia Espaço e Vivência - $8^{\circ}$ ano. Autores: Levon Boligian, Rogério Martinez, Andressa Turcatel Alves Boligian e Wanessa Pires Garcia Vidal, 6a Edição, Editora Atual, São Paulo, 2016) faz parte de uma coleção em quatro volumes que compõem o conteúdo curricular da segunda etapa do ensino fundamental, cobrindo o ensino de geografia do $6^{\circ}$ ao $9^{\circ}$ anos. Organizados de forma a oferecer uma visão da parte para a do todo, passamos pelas três abordagens geográficas no decorrer da didática do livro, sendo elas trabalhadas de forma detalhada quando necessário.

Ao mesmo tempo em que temos uma análise descritiva da natureza físico-química no conteúdo do $6^{\circ}$ ano, nos deparamos com uma análise teorético-quantitativa ao abordarmos tópicos de estatísticas populacionais no ensino do $7^{\circ}$ ano e por fim uma análise descritiva no $8^{\circ}$ e $9^{\circ}$ anos, ao analisarmos a composição dos continentes e o contexto histórico-geográfico de suas relações, embora as atividades didáticas no fim de cada capítulo tragam reflexões e estimulem a pensar de forma que a análise crítica também está presente.

No Geografia Espaço e Vivência - $8^{\circ}$ ano, objeto de estudo deste trabalho, o livro é subdivido em 6 unidades temáticas, as três primeiras detalhando noções geográficas, políticas e econômicas que serão relevantes para o entendimento das próximas três unidades em que são detalhados os continentes que compõem a maior parte do mundo subdesenvolvido do presente e as mudanças que passam no contexto de globalização das últimas décadas, notadamente América Latina, África e Ásia.

Aqui será esmiuçada a unidade V - África, subdividida em quatro capítulos, em que são detalhadas respectivamente a natureza e cultura do continente africano, as causas do subdesenvolvimento do continente africano (em que é apresentada um pouco da 
herança africana no Brasil), a conquista dos espaços geográficos do continente africano em sua busca por desenvolvimento e por fim uma discussão a respeito da indústria, economia e população da África.

Um país com uma matriz étnico-cultural tão rica quanto a do Brasil é difícil de se encontrar. Seja pela heterogeneidade de sua formação, tanto em suas origens quanto no intervalo de tempo compreendido, a cultura e identidade brasileiras são resultado de uma fermentação e amadurecimentos de inúmeras etnias africanas, culturas indígenas e costumes europeus.

Entretanto, por mais que sua tradição seja multicultural, uma experiência cosmopolita por si só, os costumes e tradições dos afrodescendentes e indígenas são relegadas ao segundo plano, pois existe "a manutenção da hostilidade e da inferiorização como fundamentos básicos para manter os contextos de exploração, da inexistência espacial e da manutenção de uma 'zona de conforto' institucionalizada de um seleto grupo da sociedade brasileira, ‘branca’ e escravocrata.” (ANJOS, 2020, p.40).

Ademais, em uma nação cuja população é composta em sua maioridade por pretos e pardos, é necessário que a sociedade esteja cultural e socialmente aparelhada para representar o povo que a compõe, e não privilegiar grupos minoritários que detiveram, e ainda detém o controle político e da informação.

Desde 1996, com o estabelecimento das diretrizes e bases da educação nacional pela lei no 9.394, o artigo 26, inciso quarto, declara que “o ensino da História do Brasil levará em conta as contribuições das diferentes culturas e etnias para a formação do povo brasileiro, especialmente das matrizes indígena, africana e europeia”. Embora vigente desde 96, é só a partir de 2003, com a reformulação do artigo supracitado, é que o ambiente escolar passa por uma transformação no ensino da ancestralidade africana e seu impacto na identidade brasileira, como também estabelece a necessidade de capacitação dos docentes para que o conhecimento possa ser transmitido de forma efetiva, estabelecendo que a cultura afro-brasileira deve ser abordada por três disciplinas fundamentalmente: Educação Artística, Literatura e História Brasileira, além de instituir o "Dia Nacional da Consciência Negra” como data letiva nas escolas de todo o país (Lei $\left.n^{0} 10.639 / 2003\right)$.

Dessa forma, foi implementada uma abordagem do impacto cultural, histórico e geográfico dos filhos da diáspora não apenas pelas perspectivas curriculares 
anteriormente citadas, como também através de uma abordagem religiosa e geográfica, como pode ser visto na Base Nacional Comum Curricular (BRASIL, 2018).

Por mais que o respaldo legal se sustente e o próprio Ministério da Educação tenha descrito quais as habilidades devem ser desenvolvidas no que tange a cultura africana e afro-brasileira a ser lecionada nas diferentes etapas do Ensino Fundamental ao Médio, como é possível garantir que este material tem chegado as mãos do discentes, emancipando e instruindo sobre a influência massiva dos negros na formação identitária brasileira?

Para tal, é necessário que se analise qualitativamente o material didático ao qual o sistema de ensino está sendo submetido, verificando se ele cumpre tanto a lei 10.639/2003 quanto se instrumentaliza o estudante para o desenvolvimento das habilidades estabelecidas na BNCC.

Neste artigo, o livro escolhido é o Geografia Espaço e Vivência - $8^{\circ}$ ano, do Levon Boligian et. al., tanto por ser o volume que cobre o ensino da África, sua formação, historiografia e influência, quanto pela disponibilidade de acesso do volume em questão. Este é o terceiro volume da coleção Espaço e Vivência, que cobre os quatro anos da segunda etapa do Ensino Fundamental. Com base no volume escolhido, espera-se que após a conclusão do $8^{\circ}$ ano letivo, o discente seja capaz de:

- EF08GE17 - Analisar a segregação socioespacial em ambientes urbanos da América Latina, com atenção especial ao estudo de favelas, alagados e zona de riscos;

- EF08GE18 - Elaborar mapas ou outras formas de representação cartográfica para analisar as redes e as dinâmicas urbanas e rurais, ordenamento territorial, contextos culturais, modo de vida e usos e ocupação de solos da África e América;

- EF08GE19 - Interpretar cartogramas, mapas esquemáticos (croquis) e anamorfoses geográficas com informações geográficas acerca da África e América;

- EF08GE20 - Analisar características de países e grupos de países da América e da África no que se refere aos aspectos populacionais, urbanos, políticos e econômicos, e discutir as desigualdades sociais e econômicas e as pressões sobre a natureza e suas riquezas (sua apropriação e valoração na produção e circulação), o que resulta na espoliação desses povos. (BRASIL, 2018, p. 391) 
Além disso, no $8^{\circ}$ ano, também se espera que a instituição de ensino guie os discentes para que:

Nessa direção, explora-se, no $8^{\circ}$ ano, uma análise mais profunda dos conceitos de território e região, por meio dos estudos da América e da África. Pretende-se, com as possíveis análises, que os estudantes possam compreender a formação dos Estados Nacionais e as implicações na ocupação e nos usos do território americano e africano. As relações entre como ocorreram as ocupações e as formações territoriais dos países podem ser analisadas por meio de comparações, por exemplo, de países africanos com países latino-americanos, inserindo, nesse contexto, o processo socioeconômico brasileiro (BRASIL, 2018, p.382).

\section{Da organização do livro}

\section{1 - Concepção Geográfica}

Como anteriormente mencionado, o livro é dividido em seis unidades de interesse, três que instrumentam os alunos com conceitos econômicos, políticos e geográficos, e três unidades em que analisamos os continentes subdesenvolvidos com as ferramentas adquiridas: África, América Latina e Ásia.

Quanto a caracterização de fauna, flora, tipos de vegetação, domínios morfoclimáticos, sistemas econômicos, organização espacial e afins, presentes na primeira metade do livro, temos uma abordagem majoritariamente descritiva, sendo alternada pela inserção de alguns dados e gráficos pertences a geografia teoréticoquantitativa, quando necessário exemplificar conceitos estatísticos ou de médias climáticas, como temperatura e pluviosidade.

Quando se dá a análise dos continentes, a perspectiva descritiva se mantém e as atividades orientadas ao fim de cada capítulo levam à reflexão crítica, como por exemplo, ao trazer os problemas enfrentados pela África como consequência de anos de exploração e o impacto da era imperialista nos continentes abordados.

Abaixo, estão representadas algumas dessas discussões propostas nas unidades da América Latina e África, salientado o parecer crítico que os questionamentos levantam. 
41 Análise da Abordagem Didática da Cultura Africana e Afro -brasileira no Livro Geografia Espaço e Vivência - 8o Ano

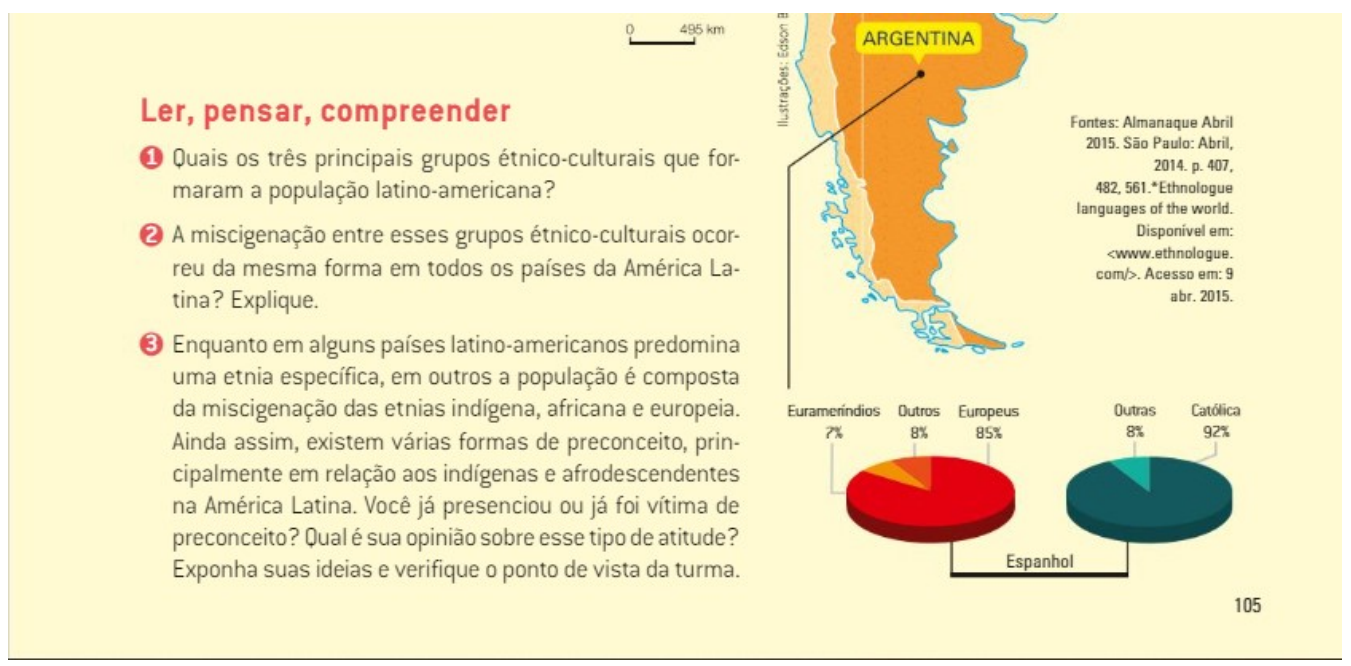

Figura 1 - Análise crítica levantada por discussões sobre a composição da América Latina (BOLIGIAN, 2016, p. 105)

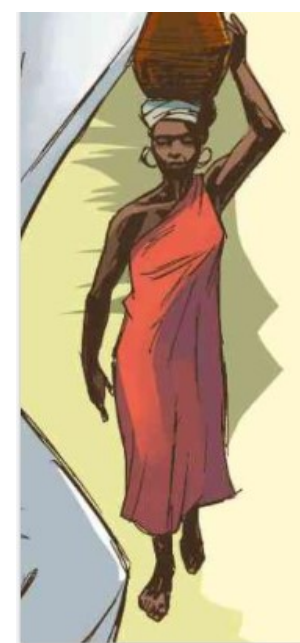

Ler, pensar, compreender

(1) 0 que significa quilombo na língua banto?

(2) Onde e quando foi criado o Quilombo dos Palmares? Quando ele foi destruído?

(3) Mesmo tendo direito de posse sobre a terra, as comunidades quilombolas espalhadas pelo território do país sofrem constantes ameaças. Quais são essas ameaças?

4 As comunidades remanescentes dos antigos quilombos são importantes para a preservação dos valores culturais da população negra? Justifique.

(5) Reúnam-se em grupos e, com a ajuda do professor, pesquisem sobre as comunidades quilombolas e os grupos de resistência negra no Brasil. Informem-se sobre os itens que seguem.

- Quem foi Ganga Zumba e Zumbi.

- Como vivem as comunidades quilombolas atualmente.

- Quais são os grupos de resistência negra mais atuantes no Brasil.

Figura 2 - Análise crítica levantada por discussões sobre a natureza dos Quilombos (BOLIGIAN, 2016, p.139)

\section{2 - Sobre o Espaço Geográfico}

As duas primeiras unidades abordam o conceito de espaço geográfico através de uma conversa franca com o leitor, construindo os conceitos de espaços naturais e espaços políticos para criar uma compreensão do que é o espaço geográfico, instrumentalizando o estudante por meio de reflexões e atividades. Feita essa ambientação, o discente vê as aplicações dos conteúdos previamente aprendidos nas unidades subsequentes.

Abaixo podem ser vistas as unidades que abordam tal instrumentação como apresentadas no sumário da edição, assim como atividades complementares no fim do capítulo que auxiliam a construir a noção de espaço geográfico. 


\section{SUMÁRIO}

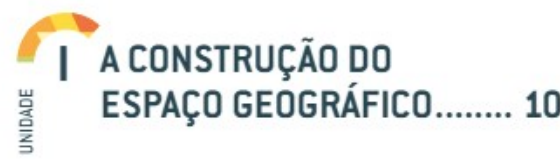

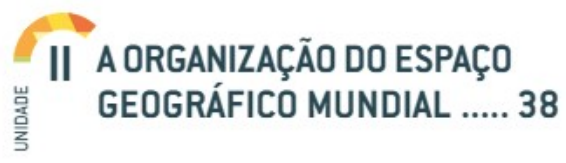

Figura 3 - Divisão de unidades norteando quanto a noção de espaço geográfico (BOLIGIAN, 2016, p.6)

\section{(1) Atividades}

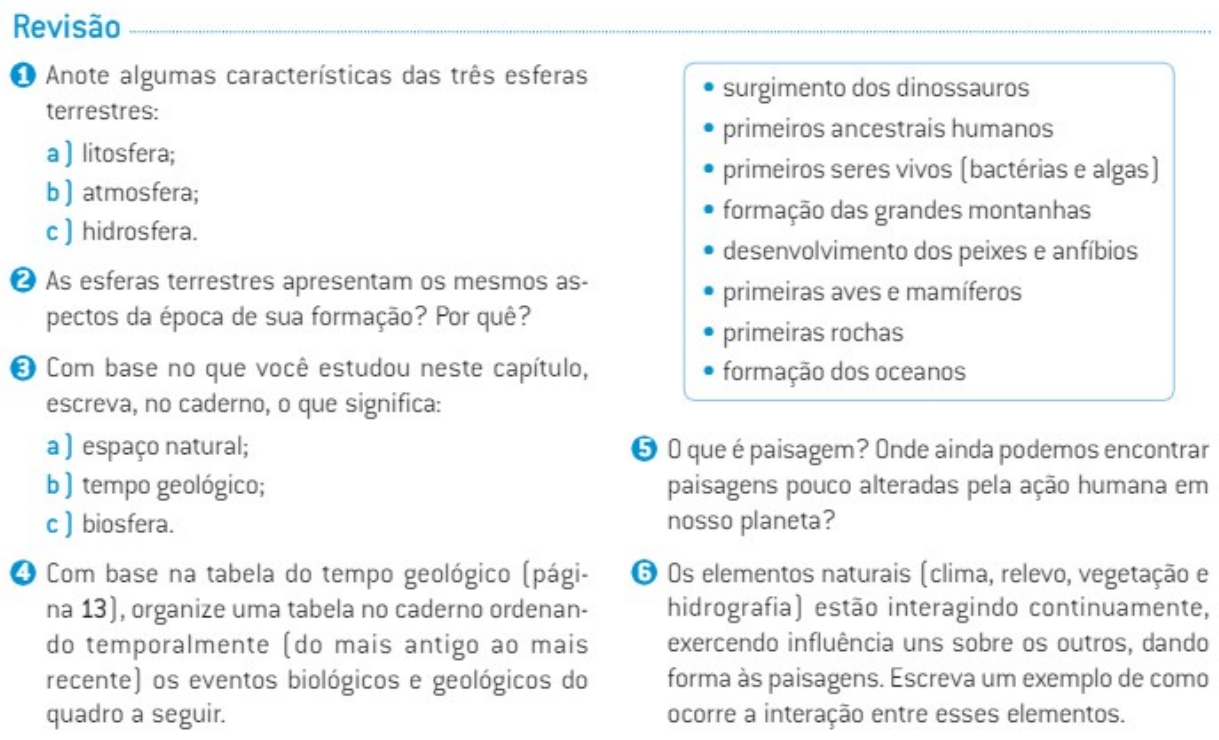

Figura 4 - Atividades de consolidação sobre espaço geográfico (BOLIGIAN, 2016, p.18).

\section{Brasil e África: representações didáticas}

Uma vez que se tem as noções necessárias de mundo, espaço, território e sistemas econômicos, exploramos o mundo de forma sistemática, conhecendo alguns dos continentes e sua organização espacial do presente, assim como as razões históricas e geográficas que o levaram a se organizar dessa forma. Notadamente, analisaremos as 
43 Análise da Abordagem Didática da Cultura Africana e Afro -brasileira no Livro Geografia Espaço e Vivência - 8o Ano

unidades quatro e cinco, que abordam respectivamente a América Latina, onde se insere o Brasil, e a África.

Como o volume traz uma abordagem em escala global, não necessariamente foca nos aspectos constitucionais da população e território brasileiros, embora tal discussão seja levantada em atividades a serem desenvolvidas, como na representada abaixo na figura 5. Cabe ao docente trazer a perspectiva afro-brasileira no contexto geográfico da formação do Brasil, que o livro auxilia com alguma bibliografia complementar. Mesmo assim, o livro introduz o conhecimento necessário para o desenvolvimento das habilidades EF08GE17 e EF08GE20 constantes da BNCC, através de atividades que consolidam o conhecimento, como consta na figura 6.

Por que alguns países se desenvolveram mais do que outros? A resposta pode ser encontrada depois de um breve estudo histórico.

A partir do século XV, com as Grandes Navegações, algumas nações europeias lançaram-se à conquista de novos territórios, apoderando-se dos continentes americano e africano, assim como de vastas regiões da Ásia, transformando essas terras em suas colônias.

Durante a colonização, as nações europeias - também chamadas metrópoles - pas saram a explorar todas as riquezas que as colônias podiam oferecer, como madeira, ouro e prata. Assim, enquanto as colônias perdiam recursos, as metrópoles enriqueciam. Para que essa exploração fosse possível, as metrópoles submeteram as populações nativas a seus interesses. Introduziram sua cultura [religiōes, línguas, hábitos alimentares], impuseram seus modos de pensar e produzir e escravizaram e dizimaram populações, desestruturando a organização social que possuíam.
}
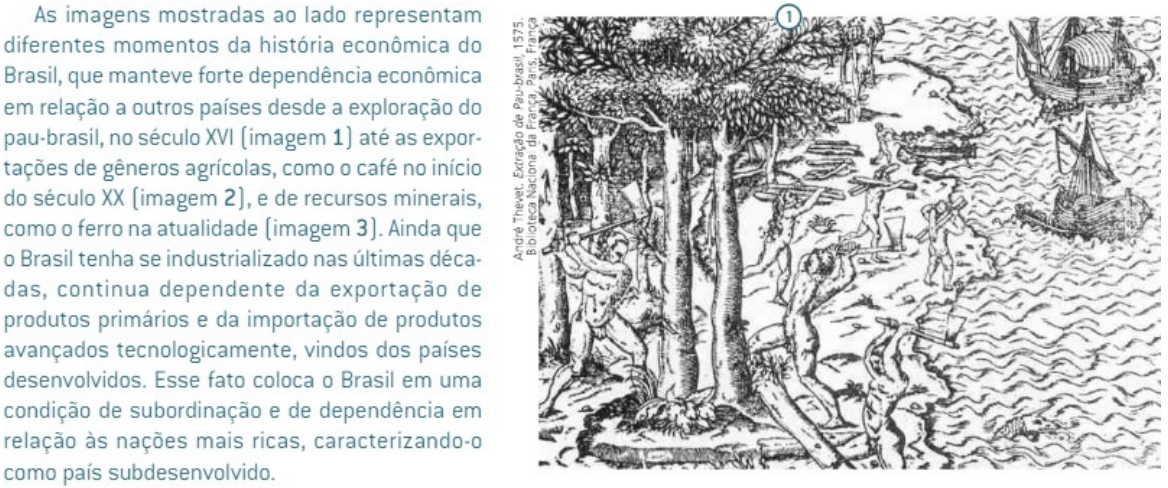

Figura 5 - Breve descrição do período colonial (BOLIGIAN, 2016, p.80) 


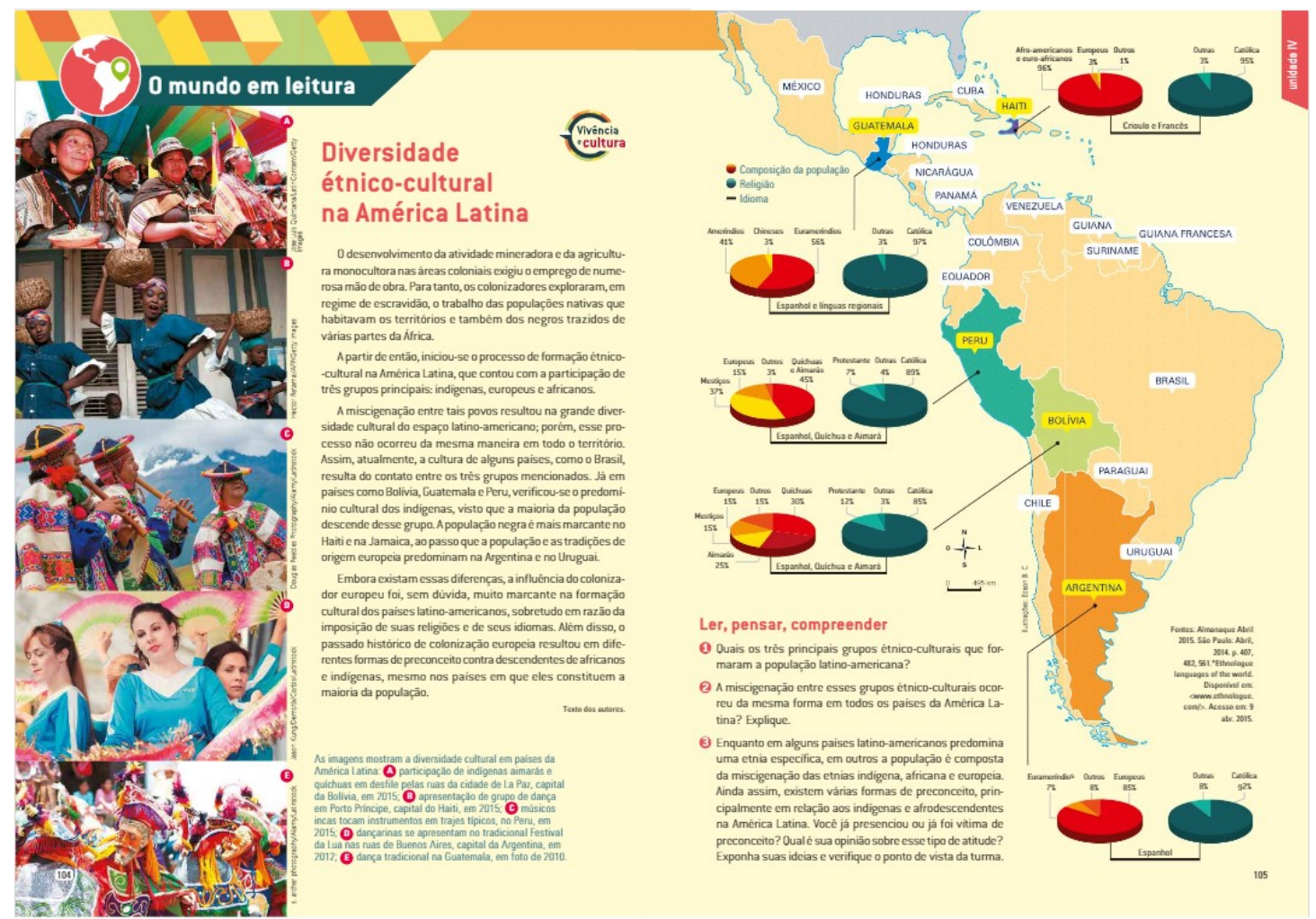

Figura 6 - Atividade de compreensão e distribuição das populações indígenas, negra e europeia na composição da América Latina (BOLIGIAN, 2016, p.104 e 105) Questionamentos sobre a formação brasileira na figura 1.

A partir de então, iniciou-se o processo de formação étnicocultural na América Latina, que contou com a participação de três grupos principais: indígenas, europeus e africanos. A miscigenação entre tais povos resultou na grande diversidade cultural do espaço latino-americano; porém, esse processo não ocorreu da mesma maneira em todo o território. Assim, atualmente, a cultura de alguns países, como o Brasil, resulta do contato entre os três grupos mencionados. Já em países como Bolívia, Guatemala e Peru, verificou-se o predomínio cultural dos indígenas, visto que a maioria da população descende desse grupo. A população negra é mais marcante no Haiti e na Jamaica, ao passo que a população e as tradições de origem europeia predominam na Argentina e no Uruguai. (BOLIGIAN, 2016, p. 104).

Sequencialmente, o livro traz por meio de uma atividade cartográfica um levantamento dos portos de saída e chegada dos contingentes negros de importação forçada, como diz Anjos (2020, p.), que compreende alguns dos principais grupos étnicos africanos e dos principais portos brasileiros aos quais estes estavam sendo transportados, como pode ser visto na figura 7. 
45 Análise da Abordagem Didática da Cultura Africana e Afro -brasileira no Livro Geografia Espaço e Vivência - 8o Ano

As relações escravocratas Brasil-África, não são apresentadas de forma detalhada, embora a cartografia de tal evento esteja intimamente correlacionada com a formação da América por inteiro, em particular do Brasil. Mesmo com esse déficit conteudista, mais uma vez provocado pela abordagem continental e global, uma vez que o enfoque no Brasil é dado em outras séries, somos apresentados ao aspecto cultural das comunidades quilombolas e é proposta uma pesquisa sobre tais comunidades, assim como das principais figuras da resistência contra a escravidão e dos seus remanescentes, questionamentos presentes na figura 2.

Também é apresentado um excerto que representa a fusão da cultura africana no Brasil, salientando as dinâmicas culturais e espaciais pelas quais passaram os africanos trazidos de suas raízes e como recriaram, ressignificaram e reimaginaram sua cultura num contexto periférico em que seu valor era dito inferior por uma elite "branca”. Tal representação consta na figura 8.

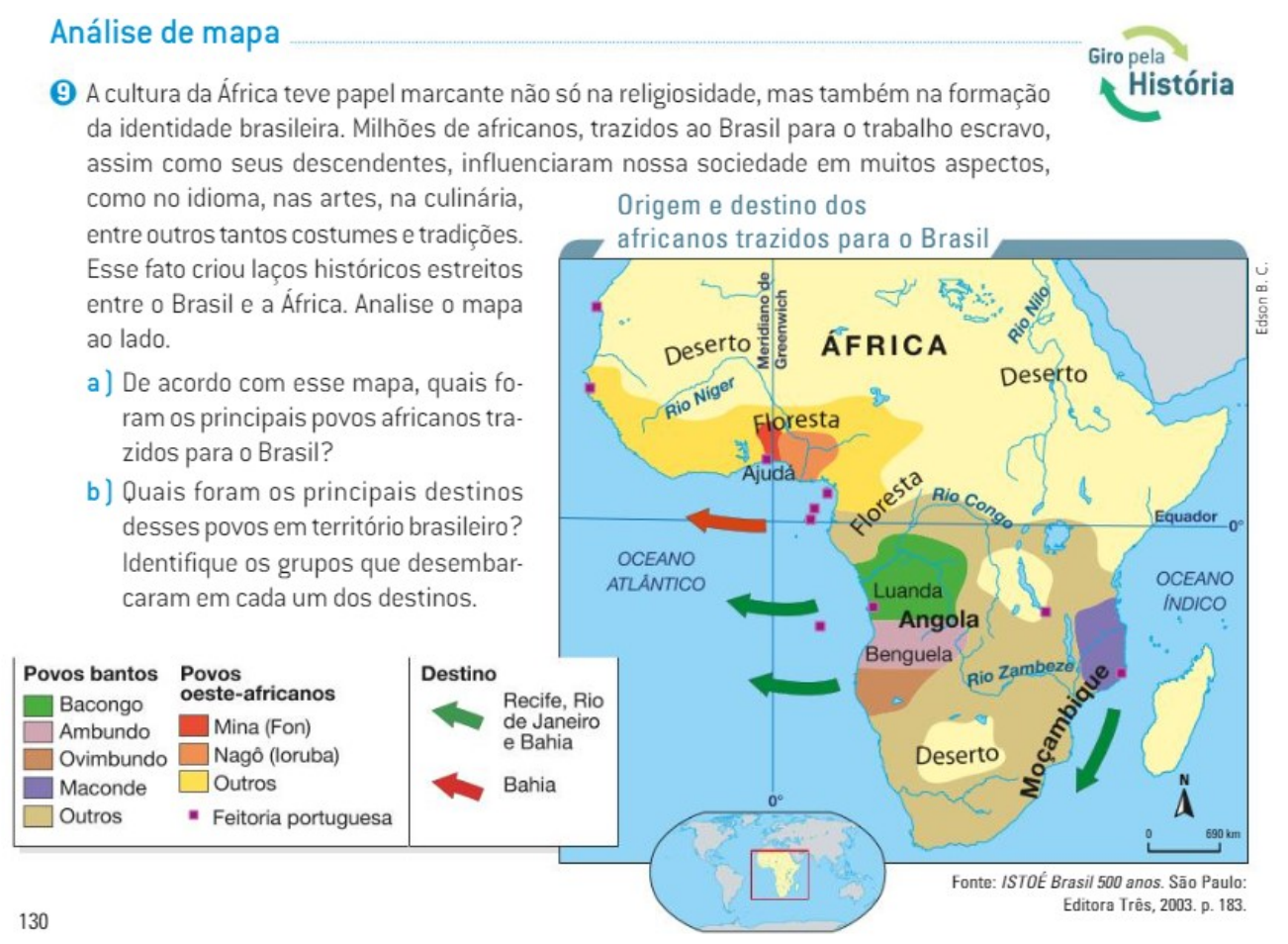


Figura 7 - Atividade da Cartografia da Diáspora (BOLIGIAN, 2016, p. 130)

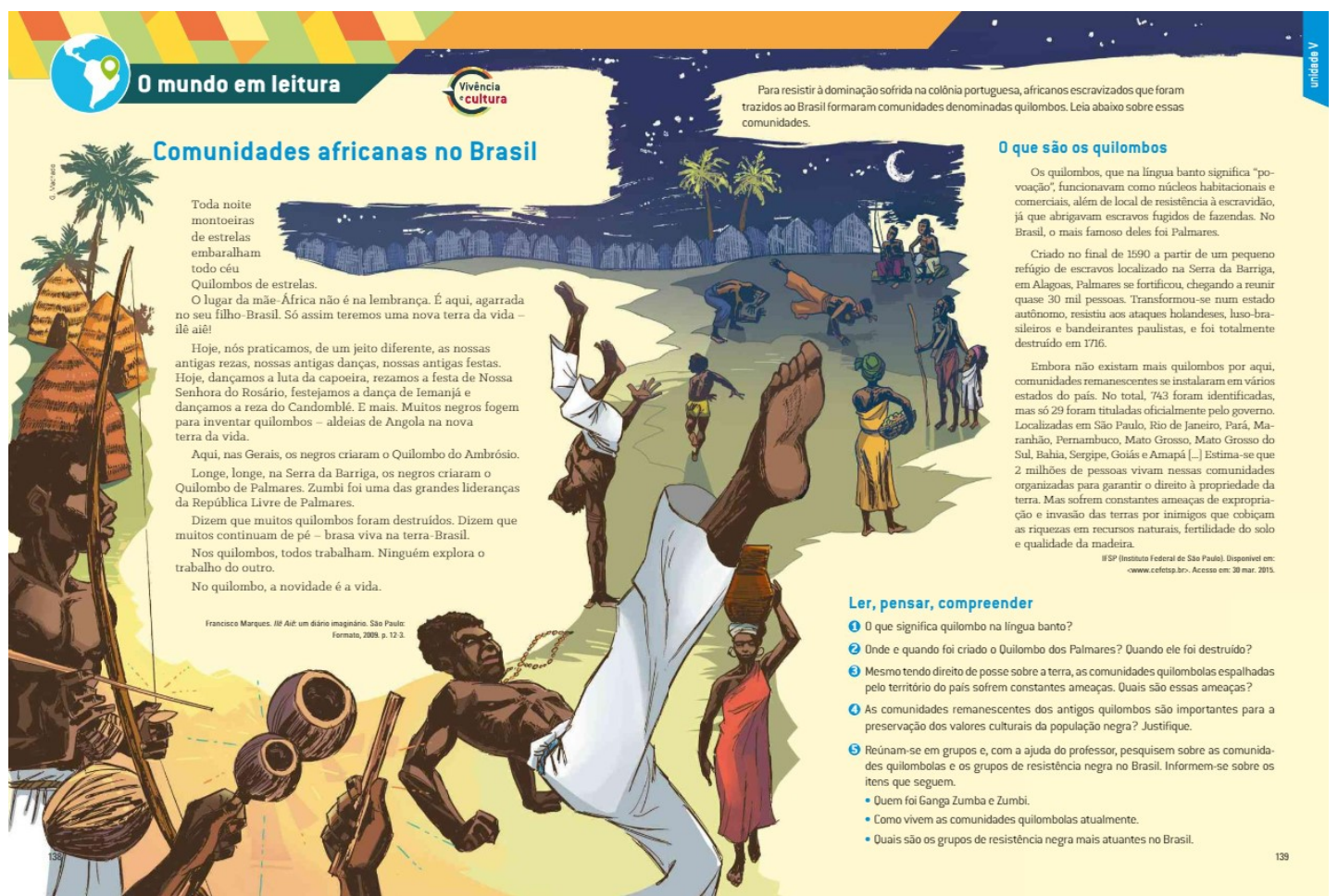

Figura 8 - Excerto Cultural das comunidades quilombolas e atividade associada (BOLIGIAN, 2016, p.

138 e 139)

“Toda noite montoeiras de estrelas embaralham todo céu. Quilombos de estrelas. O lugar da mãe-África não é na lembrança. É aqui, agarrada no seu filho-Brasil. Só assim teremos uma nova terra da vida - ilê aiê! Hoje, nós praticamos, de um jeito diferente, as nossas antigas rezas, nossas antigas danças, nossas antigas festas. Hoje, dançamos a luta da capoeira, rezamos a festa de Nossa Senhora do Rosário, festejamos a dança de Iemanjá e dançamos a reza do Candomblé. E mais. Muitos negros fogem para inventar quilombos - aldeias de Angola na nova terra da vida. Aqui, nas Gerais, os negros criaram o Quilombo do Ambrósio. Longe, longe, na Serra da Barriga, os negros criaram o Quilombo de Palmares. Zumbi foi uma das grandes lideranças da República Livre de Palmares. Dizem que muitos quilombos foram destruídos. Dizem que muitos continuam de pé - brasa viva na terra-Brasil. Nos quilombos, todos trabalham. Ninguém explora o trabalho do outro. No quilombo, a novidade é a vida.” (MARQUES, 2009, p. 12-3. Apud BOLIGIAN, 2016, p. 138).

A partir daí, o livro apresenta uma análise do cenário contemporâneo da África, e as dificuldades que encontra no seu desenvolvimento socioeconômico, causado pelas 
47 Análise da Abordagem Didática da Cultura Africana e Afro -brasileira no Livro Geografia Espaço e Vivência - 8o Ano

práticas imperialistas dos quinhentos anos anteriores. Temos retratos de miséria, fome e escassez, em sua maior parte, além do extrativismo e da agricultura de subsistência e o descaso geral com a população, pela qual passa o continente africano.

De forma geral, não se vê o cenário brasileiro e afrobrasileiro representado neste livro, além de algumas poucas manifestações culturais e grupos étnicos africanos (figura 9), nem representações estereotipadas desses cenários, apenas figuras que retrataram as políticas imperialistas (figura 10). Ainda que não haja a representação estereotipada, a maior parte das ilustrações e fotografias inclusas, denota o negro numa posição subjacente a do branco, nunca superior, sempre inferior (figura 11).

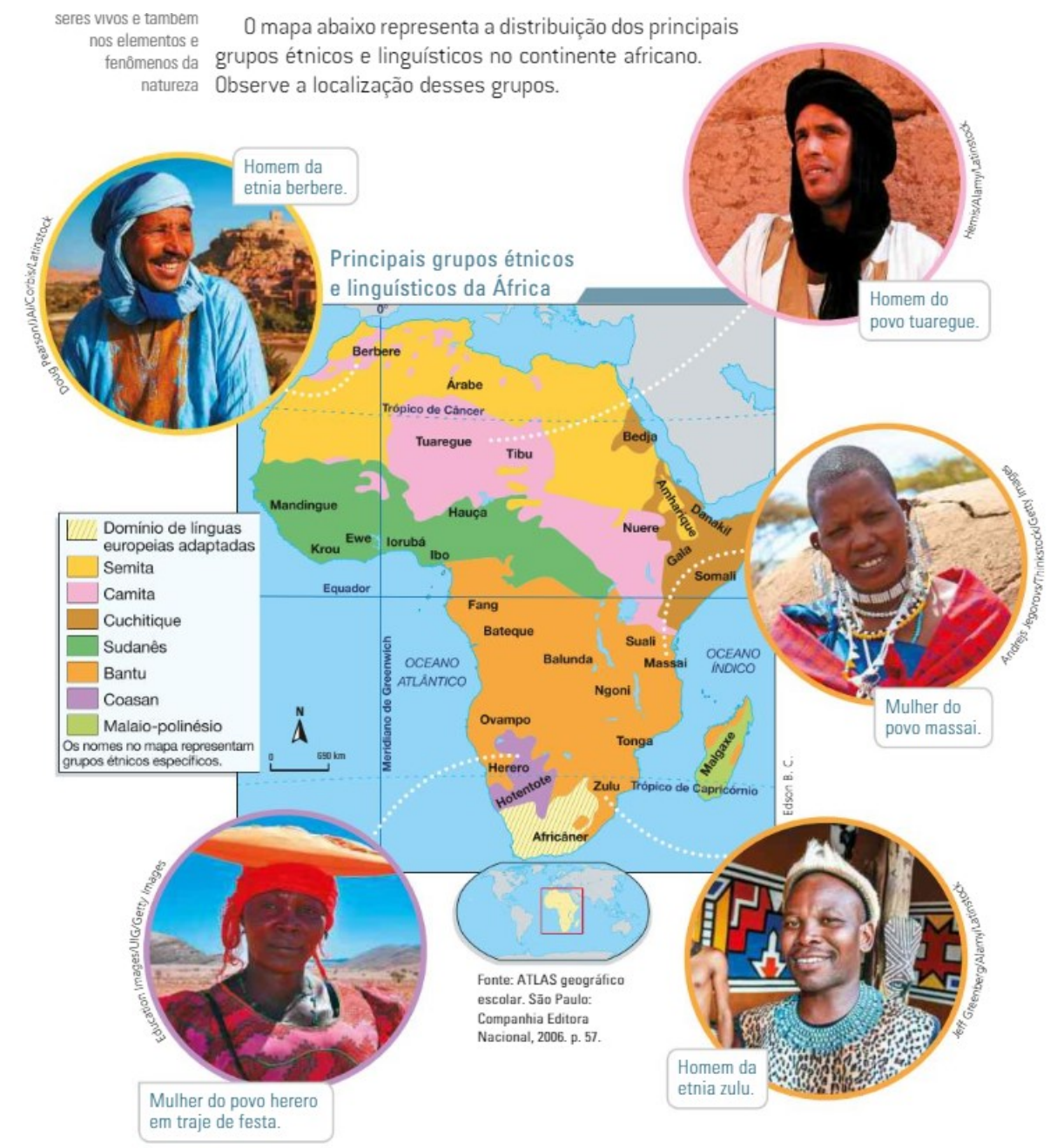

Figura 9 - Representação étnica de alguns grupos do continente africano (BOLIGIAN, 2016, p.128) 

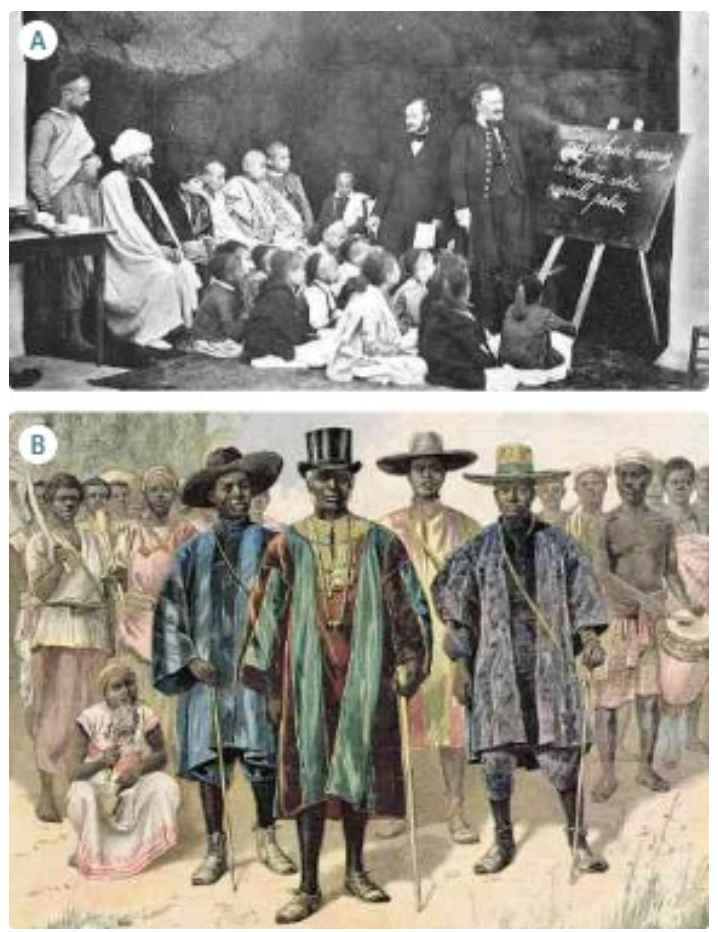

Figura 10 - Retratos do imperialismo na África (BOLIGIAN, 2016, p.134).

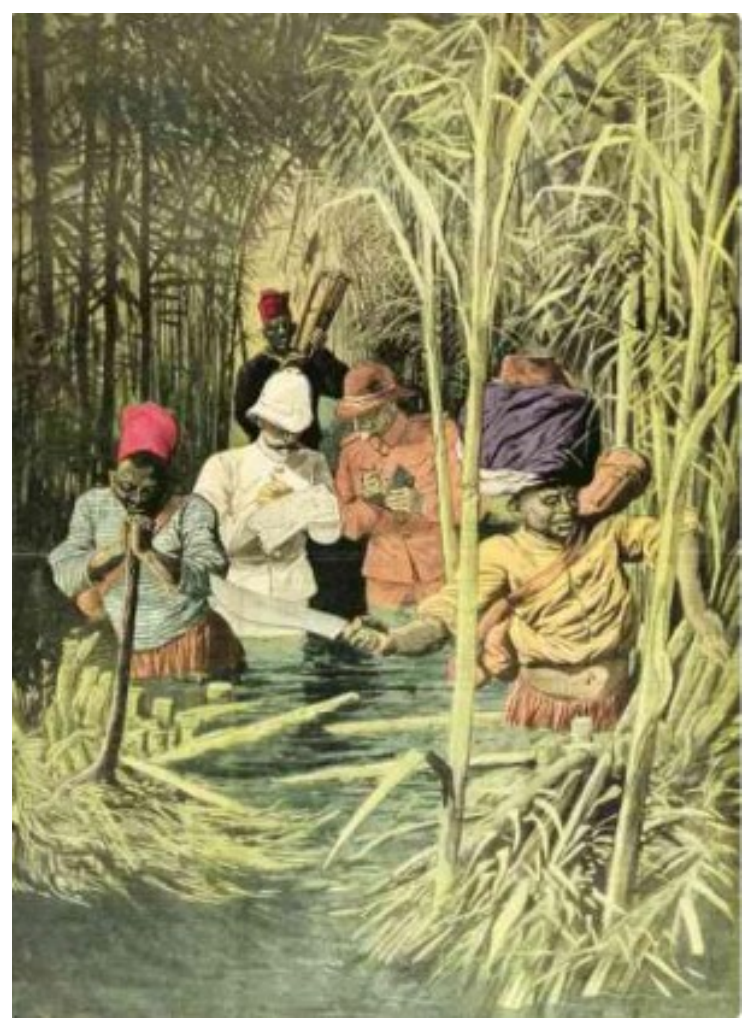

Figura 11 - O negro subjacente ao branco numa expedição de delimitação política do Congo em 1913 (BOLIGIAN, 2016, p.132).

Uma vez que o contexto miscigenado da formação da população brasileira não é explicitado, como feito para alguns outros países da américa latina na subsecção já explicitada na figura 6, cabe ao discente fazer essa pesquisa junto ao questionário da 
figura 1 e ao docente ampliar essa discussão para compreender as raízes dessa miscigenação, com um pouco de aplicação do questionário presente na figura 2, construindo o conhecimento não de forma geográfica e continental, mas de forma global e historiográfica.

Dessa forma, o livro não traz aspectos relevantes da composição populacional brasileira de forma qualitativa, embora dê um simulacro de fundações sobre as quais questões críticas sobre o papel da África no Brasil possam ser compreendidas em sala de aula, assim como as dinâmicas sociais, econômicas e da organização dos espaços geográficos das metrópoles brasileiras. Essa abordagem é coerente com a proposta didática do livro de trazer uma visão globalizada da economia dos continentes e sua formação geográfica e morfoclimática.

\section{Conclusão e Discussões}

Este volume em particular não afirma enfaticamente, embora lance as sementes de investigação para os alunos construírem o conhecimento e entendimento do Brasil Africano, como se espera das habilidades de geografia que desenvolvam no $8^{\circ}$ ano, segundo a BNCC (BRASIL, 2018, p. 391).

Considerando a distribuição populacional de maioria negra, os pardos inclusos, parece um desserviço que o continente africano, tão vital na formação do Brasil e da América Latina como um todo, só tenha unidades formadoras de opinião sobre o assunto em três ou quatros seções de atividades, embora, considerando o caráter majoritariamente descritivo do livro didático escolhido, tal fato seja coerente com a metodologia, mesmo que não seja coerente com a necessidade de formação multicultural que a nação brasileira necessita em sala de aula para a construção de uma sociedade livre do racismo e do preconceito.

Depende do discernimento do professor em sala de aula, seguindo as orientações da BNCC, para instrumentalizar o pensamento crítico da formação da identidade brasileira como resultado da miscigenação de negros, indígenas e europeus, dando maior destaque ao primeiro grupo, que constitui maioria da nação brasileira. Como o conhecimento em sala de aula não é construído apenas através das atividades prescritas pelo livro didático, uma abordagem multidisciplinar pode ser uma excelente saída para que os estudantes conheçam e entendam a sua herança cultural, herança essa que é vital 
na formação da identidade do país. Aproveitando-se da abordagem da cultura afrobrasileira por outros ângulos, como através da literatura, arte e história, é possível se construir um conhecimento mais integrado da África como patrona ancestral das sementes identitárias do Brasil moderno.

Além disso, o florescimento da cultura afro-brasileiro e africano nas mídias sociais é um importante avanço no entendimento de que existe muita cultura e história na África, que geralmente é retratada pela abordagem única da escravidão. A emancipação dos povos africanos vem acontecendo desde o século anterior, com a sua independência, mas agora passamos a uma conscientização mundial de toda a riqueza cultural que a África tem a oferecer, seja conhecendo suas múltiplas mitologias, do Vale do Nilo ao norte islâmico, ao animismo sub-saariano e as crenças iorubás das costas ocidentais, ou através de retratos da vida real, como de Chimamanda Ngozi, de William Kamkwamba ou ainda de Fatou Ndiaye, o pluriculturalismo das etnias africanas e afro-brasileiras tem muito a influenciar no mundo, conscientizando uma escola por vez.

Cabe a nós somente dar a África sua devida importância dentro do cenário de ensino brasileiro.

\begin{abstract}
Ainda em relação à diversidade cultural, cabe dizer que se estima que mais de 250 línguas são faladas no país - indígenas, de imigração, de sinais, crioulas e afro-brasileiras, além do português e de suas variedades. Esse patrimônio cultural e linguístico é desconhecido por grande parte da população brasileira. (BRASIL, 2018, p.70).
\end{abstract}

Por mais que os esforços para a conscientização e conhecimento da cultura africana e afro-brasileira tenham sido intensificados nos últimos anos, ainda há um longo caminho a ser percorrido para que a sociedade possa se ver livre do pensamento colonial que a permeia, enxergando somente os grilhões impostos à África por cinco séculos e não suas raízes ricas e profundas, nem as sementes de um futuro brilhante e rico.

Não cabe somente a geografia instrumentalizar e ensinar a respeito do Brasil africano, embora detenha um papel fundamental, como também aos demais componentes curriculares do ensino básico construir uma cultura de reconhecimento e respeito. Dessa forma, através de uma formação multidisciplinar abrangendo a história, o espaço geográfico e as manifestações culturais que a África detém na identidade nacional, será possível a emancipação dos povos negros no Brasil, numa sociedade livre do racismo estrutural e consciente de sua ancestralidade negra. 
51 Análise da Abordagem Didática da Cultura Africana e Afro -brasileira no Livro Geografia Espaço e Vivência - 8o Ano

\section{Bibliografia}

BOLIGIAN, L. et al. Geografia espaço e vivência $8^{\text {0 }}$ ano. 6. ed. São Paulo: Atual, 2016. $226 \mathrm{p}$.

BRASIL. Lei no 10.639, de 9 de janeiro de 2003. Diário Oficial da União, Brasília, 10 de janeiro de 2003. Disponível em: <http://www.planalto.gov.br/ccivil_03/leis/2003/L10.639.htm>

BRASIL. Ministério da Educação. Base Nacional Comum Curricular. Brasília, 2018. Disponível em: $<$ http://basenacionalcomum.mec.gov.br/images/BNCC_EI_EF_110518_versaofinal_site .pdf $>$

ANJOS, R.S.A (2020). Territórios Invisíveis do Brasil Africano: Cartografias e Tensões Sócio-Espaciais nos Terreiros Religiosos. In: REGO, N. \& KOZEL, S. (Orgs.) Narrativas, Geografias \& Cartografias - Volume 1. Eds. COMPASSO e UFRGS Geociências: Porto Alegre, 2020. Disponível em: < https://c1a1c6c2-aa2b-46b496445425a5ead160.usrfiles.com/ugd/c1a1c6_38589f2446ce4ebb8ff34dcece9117f3.pdf . 